\title{
POLÍTICAS LINGUÍSTICAS CONVERGENTES E DIVERGENTES NO ENSINO DE PORTUGUÊS - LÍNGUA ESTRANGEIRA
}

\author{
Rosemeire Selma Monteiro Plantin* \\ Maria Erotildes Moreira e Silva*
}

\begin{abstract}
RESUMO: Apresentamos, nesse artigo, as crenças e práticas de 75 docentes que atuam na promoção do português, no cenário internacional, com o objetivo de registrar a visão desses profissionais acerca de instrumentos imprescindíveis à difusão do português, no atual cenário. Sob a perspectiva de Spolsky (2004), a quem uma Política Linguística (PL) não deve desconsiderar seus agentes, analisamos, então, os Programas de Leitorado, a escassez de material didático e a incipiente formação de professores, enquanto instrumentos de promoção do português. Ao traçar esse panorama, concluímos que há um distanciamento entre as políticas oficiais e as necessidades dos professores que atuam nessa área, de forma geral. Portanto, com essa reflexão, pretendemos contribuir para a diminuição do hiato entre essas ações oficiais e as práticas desses profissionais, além de reforçar a necessidade de um incremento à formação político-pedagógica dos grupos responsáveis pela promoção de uma língua com as características do português.
\end{abstract}

PALAVRAS-CHAVE: Política linguística; Planejamento linguístico; Ensino de PLE.

\footnotetext{
* Professora da Universidade Federal do Ceará (UFC). Doutora em Psicolinguística pela Universidade Federal de Santa Catarina (Ufsc).

** Professora de Língua Portuguesa desde 1987 e bolsista CAPES-PNPD, vinculada ao grupo de pesquisa PLIP_ UFC (Programa de Políticas Linguísticas para a Internacionalização da Língua Portuguesa). Desenvolve pesquisas no Programa de Pós-Graduação em Linguística da Universidade Federal do Ceará acerca das políticas linguísticas para a internacionalização do português e atua em pesquisas para a elaboração de material didático destinados ao ensino de português como língua estrangeira (PLE).
} 


\section{Considerações iniciais}

As políticas linguísticas (PL) integram a base da internacionalização de uma língua, desde que o homem, ao conquistar um território, o fez com a imposição do idioma do conquistador e de suas práticas culturais no universo conquistado. Nessa perspectiva, a ampliação de um território geolinguístico pode ocorrer de forma contundente, seja pela inserção política do idioma em diferentes esferas do espaço (a ser) conquistado, por diferentes vias, como o ensino, seja pela obrigatoriedade do uso da língua, através de leis e decretos.

A internacionalização, desse modo, é constituída por ações que, no dizer de Spolsky (2004;2008) e Shohamy (2006) devem ser elaboradas a partir de uma engrenagem que considere o terreno geolinguístico em que a língua está inserida, a comunidade que a fala e a institucionalização de políticas ou de instrumentos que considerem a configuração global da língua e as necessidades dessa comunidade.

Embora essa não fosse a perspectiva das PL em torno do português, nas "trocas linguístico-culturais" realizadas entre jesuítas, soldados portugueses e nativos, nos anos de 1500, quando as naus lusitanas se apropriaram desse pedaço da América do Sul, os avanços nessas PL nos permitem afirmar que se faz necessário um olhar mais acurado sobre os aspectos sociolinguísticos e político-ideológicos que perpassam uma língua, para além de uma medida implementada por uma lei, um decreto ou por parâmetros que norteiem a difusão e o ensino de um idioma.

Desse modo, nesse artigo, lançamos uma reflexão sobre as interfaces entre a gestão da língua portuguesa e o ensino do idioma, no cenário internacional, a partir das crenças e práticas de gestores e professores que atuam na difusão e promoção do português, em diferentes países, com o objetivo de ampliar as discussões acerca desse tema que a nós parece fulcral, no atual contexto.

Metodologicamente, partimos da visão desses dois autores e das necessidades desses dois grupos, por comungarmos da visão de que uma Política Linguística deve ter como base a comunidade à qual foi destinada. Os excertos aqui apresentados são um recorte de 
nossa pesquisa doutoral (SILVA, 2015) e foram colhidos em entrevistas semi-estruturadas realizada em 2013, em diferentes países.

Foram entrevistados, portanto, três gestores que atuam na difusão do português e oito professores que atuam na esfera privada - em academias (cursos de línguas espanhóis) e na preparação de candidatos aos exames de proficiência em Língua Portuguesa, nas cidades de Granada, Cáceres, Extremadura e Madri, na Espanha e em Frankfurt, na Alemanha. Já na esfera oficial, foram entrevistados quatro docentes vinculados às universidades espanholas, os quais atuam, sobretudo, nos Centros de Lenguas ou nos cursos de graduação e pósgraduação de universidades espanholas.

Os participantes do estudo foram convidados por sua atuação na promoção internacional do português, como os gestores, que são linguistas convidados pelas instituições oficiais para contribuírem com o processo, ou atuam no ensino de PLE, por escolha profissional, como os professores.

Nossa escolha por esses dois grupos ocorreu em função de nossa crença na importância política desses agentes do processo de internacionalização do português e nos levou a questionar em que medida há espaço nas políticas oficiais para ações que atendam as necessidades desses gestores e professores de PLE, em um momento em que a internacionalização da língua portuguesa vive um recrudescimento, nas palavras de Diniz (2012) e dos gestores entrevistados em nossa tese, provocado, principalmente, por interesses político-econômicos e sociais, oriundos de uma nova configuração mundial, conforme apresentado em nossa pesquisa doutoral (SILVA, 2015).

Ao ressaltar as convergências e divergências entre as ações oficiais e as crenças e práticas desses dois grupos, não pretendemos diminuir ou apagar as conquistas realizadas até então, pois vemos essas PL como um caminho que se faz a cada mudança políticosocial. Nosso objetivo é discutir a necessidade de ações consistentes, que atendam às necessidades dessa lusosfera contemporânea.

Para isso, apresentamos as PL existentes que estão relacionadas ao ensino de PLE e as analisamos a partir desses excertos, o que nos leva a reforçar nossa posição de que uma 
ação contínua e harmônica entre os países e instituições que percebem o valor estratégico do português é uma possibilidade para ampliar o espaço geolinguístico do português.

Nesse momento, por exemplo, o ensino de PLE tem apresentado demandas específicas, como o atendimento a grupos de refugiados que buscam o Brasil e Portugal, principalmente. Esse fato, dentre outros, sustentam a busca por políticas que contemplem ações consistentes ao ensino de PLE, seja na elaboração de material didático, seja na formação de professores que precisam atender a essa demanda, por exemplo.

Na medida do possível, essa demanda tem sido atendida, através de ações oficiais e não oficiais, como a elaboração de cursos de português, na perspectiva do acolhimento ou em formações pontuais, com vistas ao atendimento dessa demanda, mas não há uma orquestração de ações que atuem na perspectiva de um avanço à solidificação de uma PL em que o espaço geolinguístico do português seja ampliado, com base nas necessidades da comunidade linguística.

O conceito contemporâneo de Política Linguística já aponta que decisões formalizadas sobre a língua são perpassadas por determinadas engrenagens, em posições bem delineadas por vários autores, dentre os quais destacamos Calvet (2007), Spolsky (2008) e Fiorin (2009, p. 01), uma vez que "a língua é atravessada pela política, pelo poder, pelos poderes".

Dentre essas visões, pautamos nossa análise em Spolsky (2004), para ressaltarmos que qualquer PL deve ser elaborada a partir de três esferas interconectadas: a gestão da língua, as crenças ou ideologias sobre a língua e os discursos em torno e/ou através dela, que são sustentados por determinados grupos e por suas práticas ou ações realizadas sobre um idioma, implementadas por via oficial ou extraoficial, de acordo com as necessidades dessa comunidade linguística.

Desse modo, uma ação oficial, no tocante à língua portuguesa, deve considerar as relações estabelecidas na engrenagem a seguir: 


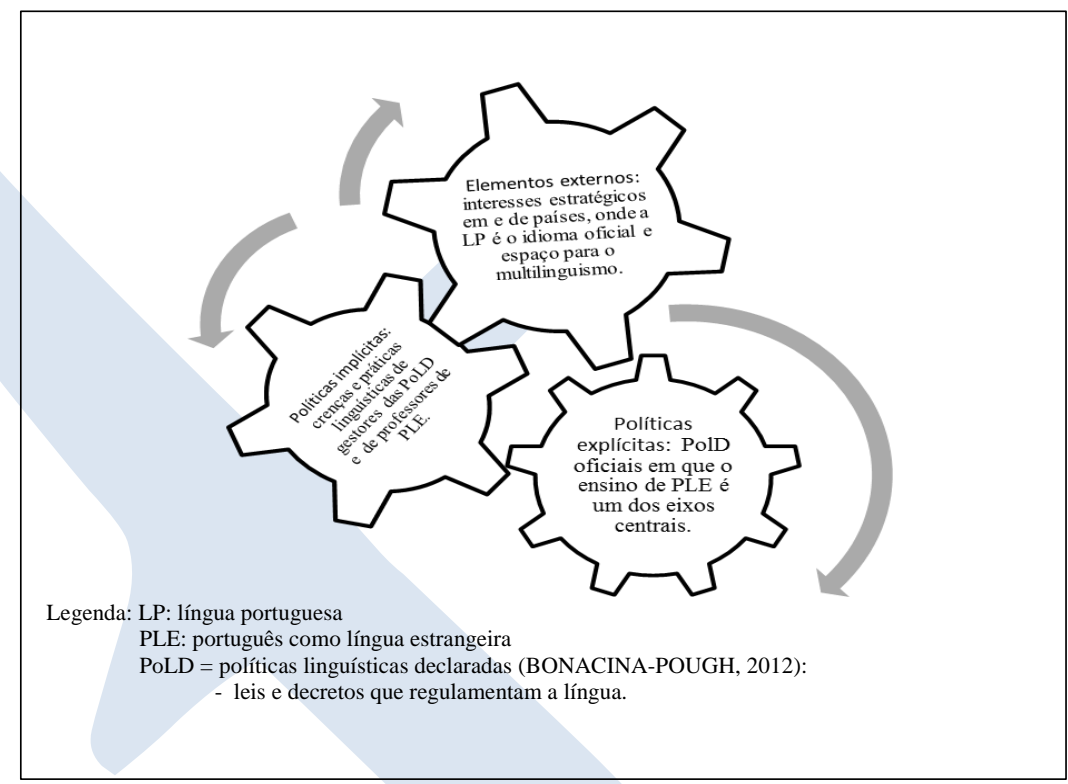

Figura 01

Fonte: criação nossa

Essa engrenagem traduz nossa visão sobre os eixos a serem considerados na elaboração, implementação e análise de uma PL voltada ao português, uma vez que o atual contexto econômico e as ideologias conflitantes em torno do idioma exigem que as ações oficiais considerem essas influências. Esses interesses desvelam um espaço a ser ocupado, em que essas práticas linguísticas explícitas e implícitas podem ser parâmetros, em uma ação multilateral sobre a língua.

Em ato contínuo, tais práticas serão modificadas em função de novas exigências político-econômicas e sociais, tais como a expansão do mercado linguístico, no dizer de Bourdieu (1996), que considera a valoração de uma língua em uma dimensão proporcional ao seu uso por uma determinada classe. 
Assim, a língua se transforma em capital linguístico que, por sua vez, é dominado por estruturas globais, em um círculo vicioso, em que a língua dominante apaga as demais, embora esteja subjugada a uma determinada situação socioeconômica e político-ideológica, a qual representa e é representada.

No caso do português, resta-nos avaliar tais ações, tendo como ponto de partida essas interseções, para compreender a razão desse(s) ocultamento(s), que, nas palavras de Shohamy (2006), são responsáveis por perpetuar ideologias hegemônicas e homogêneas, através de determinados mecanismos como a educação linguística monolíngue ou a eleição de determinados padrões, em detrimento das variantes linguísticas que constituem quaisquer línguas, por exemplo.

A autora ressalta, ainda, que não há clareza em relação ao poder desses mecanismos nas políticas linguísticas explícitas e implícitas, em relação ao modo como os falantes percebem o valor social de uma língua, mas suas escolhas podem determinar as ideologias da população em relação à (des)valorização de um idioma e, se consideradas pelos legisladores, podem determinar algumas posturas quando da elaboração de mecanismos que interferem na gestão de uma PL, na percepção e no uso de um idioma.

Assim, acreditamos que o reconhecimento das necessidades e aspirações de grupos envolvidos com a difusão de uma língua pode fornecer elementos para a ampliação de ações oficiais e não oficiais que, de fato e de direito, possam contribuir para o fortalecimento da língua portuguesa. Nessa perspectiva, apresentamos, a seguir, as convergências e divergências entre as ações oficiais e as crenças de profissionais responsáveis pelo fortalecimento e difusão do português, no cenário internacional.

\section{A gestão da língua e o ensino de PLE: convergências e divergências}

Ao entrevistar professores sobre suas necessidades em relação ao ensino de PLE, lhes apresentamos as ações oficiais em que o ensino é o eixo central. Desse modo, os 
participantes desse estudo expuseram suas percepções sobre os Programas de Leitorado ${ }^{1}$ e, por extensão, sobre a formação de professores e o material didático para PLE, tendo em vista que a internacionalização de um idioma pode ocorrer em diferentes vertentes, conforme sinalizado por um gestor desse processo de internacionalização:

Vamos tratar de quatro pontos distintos e essenciais ao processo: o interesse de alunos de diferentes espaços, a avaliação da proficiência, a qualificação. Dentre as nossas ações, a menina dos olhos, hoje, é a Noruega e o interesse de pessoas de diferentes espaços no português. (03G15a/PRT-Iof). ${ }^{2}$

A fala desse gestor, com quinze anos na área, revela campos de ação distintos que se coadunam em torno do ensino de PLE ou de Ensino de Português no Exterior (EPE), como designado pelo Estado lusitano, uma vez que, em Portugal, o PLE é o foco da ação em universidades estrangeiras e o EPE tem como campo de atuação o ensino do idioma, na Educação Básica, em diferentes países e diásporas, em uma clara assunção do valor estratégico da língua, conforme reitera esse mesmo gestor:

[...] portanto, temos que ter a visão estratégica de perceber que em aprendendo português, há uma aprendizagem com objetivos estratégicos importantes nas relações entre países que não falam português e os que falam. O desenvolvimento que a China está a ter, em relação ao português, é um grande exemplo [...] Mas, voltando... é... àquela primeira das quatro ações - com licença, quero reforçar... é... - a que referimos no início: um quadro de referência para o ensino do português, que nós temos, ao qual tomamos como referência o

\footnotetext{
${ }^{1}$ O Programa de Leitorados pode ser definido como uma política linguística, que consiste no envio de professores a universidades estrangeiras para ensinar português e difundir a cultura lusitana ou a brasileira, além de formar professores com essa finalidade, de acordo com a linha de trabalho do país responsável pela seleção do profissional. Informações disponíveis em: http://redebrasilcultural.itamaraty.gov.br, no Brasil e www.institutocamoes.pt., em Portugal. Acesso: junho de 2016.

${ }^{2}$ Os participantes do estudo foram selecionados por sua atuação na promoção internacional do português, como os gestores, que são linguistas convidados pelas instituições oficiais para contribuirem com esse processo, ou atuam no ensino de PLE, por escolha profissional, como os professores. Para apresentá-los ao longo da análise, criamos um código que traduz a ordem em que o participante foi entrevistado, a função do/a entrevistado/a, marcada pela letra $(\mathrm{G})$ para gestor e $(\mathrm{P})$ para professor, seguida do tempo em que atuam na área, do país onde a entrevista foi realizada e do tipo de instituição onde trabalham, no seguinte formato: 03G15a/PRT-Iof, indicando que um dos entrevistados foi o terceiro gestor a ser ouvido, cuja atuação na área está a completar quinze anos, em Portugal, em uma instituição oficial.
} 
interesse dos alunos que estão nas Diásporas e que, portanto, nos dá uma visão do português como PLH - é o QuaREPE - que já está no início de sua regulamentação no Ministério da Educação, em que assumimos como fator de crescimento a qualificação para o ensino e, com ele, também as provas de proficiência linguística. (03G15a/PRT-Iof)

Porém, em depoimentos colhidos junto aos professores do PE no exterior, notamos um distanciamento entre a política estabelecida pelo Estado e o alcance dessas ações, principalmente em relação à ausência de material didático:

[...] Relativamente ao material didático disponível na Universidade é... pra o português é um pouco escasso... há sempre algo a inovar... tanto a nível dos manuais didáticos, da língua mesmo, como as obras literárias disponíveis... tudo isso é importante... novas gramáticas... temos alguma coisa, mas penso que poderia ter muito mais. (02P02a/ESP-Iof)

Paradoxalmente, na Galiza as condições para aprender português são ótimas do ponto de vista do conhecimento passivo da língua de qualquer galego; porém as possibilidades de o ensinar na educação secundária são mesmo difíceis: apesar da procura crescente de parte do alunado, ainda não existem vagas para o professorado que, para o lecionar, deve superar numerosos entraves administrativos. No que diz respeito ao material didático e à formação, depende do interesse e empenho pessoal do docente ao ser escassa a oferta pública. (12P14a/GAL-Iof).

Deixa a desejar, por isso há sempre a necessidade de didatizar materiais novos, principalmente para alunos do nível avançado. (C12). (14P06a/GLZ-Ipr)

No Brasil, pela via oficial, a difusão do português está a cargo da Rede Brasil Cultural, constituída por instituições com fins diversificados, como os Centros Culturais Brasileiros, os Núcleos de Estudos Brasileiros e um Programa de Leitorado, em uma ação que também congrega ensino e promoção da língua e cultura brasileiras, com características semelhantes a Portugal, quanto às funções do professor-leitor.

Essas convergências no modus operandi dos dois países revelam uma tendência observada no modo como a gestão da língua é administrada pelas duas nações: as ações são 
pautadas na divulgação da língua e da cultura de cada país, em um "Tratado de Tordesilhas" em que cada país promove suas variedades linguísticas.

Além disso, há o fato de serem tuteladas por Ministérios que atuam na esfera internacional, em um claro indicativo do interesse estratégico dos dois países em outros espaços em que o português tem uma mais-valia, embora tal intenção não seja explícita, principalmente pelo Brasil, que denomina essas ações de diplomacia cultural voltada a países com os quais o Brasil pretende estabelecer parcerias, em face da ampliação do mercado econômico e geopolítico que tem marcado as relações transcontinentais e transnacionais, nesse início do século XXI.

A ação do Leitor brasileiro, de acordo com os depoimentos colhidos, é tão abrangente quanto a do Leitor português, principalmente, em relação à divulgação das manifestações culturais, ao mesmo tempo em que os professores sofrem a carência de material didático e de uma formação específica para PLE, tanto na esfera oficial quanto nas instituições privadas, referendando a posição de Almeida Filho (1997).

Percursor nas reflexões sobre o ensino-aprendizagem de PLE, o autor chama a atenção, ao longo de sua obra, para as especificidades entre formação docente e ensino de línguas propriamente dito e argumenta, ainda, acerca da importância de oferecer teorias formais aos docentes de línguas, tais como a apresentação de filosofias específicas de ensino-aprendizagem, métodos, abordagens, técnicas e recursos para que assim possam dar origem a uma prática pautada no conhecimento crítico e orientada à contínua reflexão, além de discutir o Português como língua de cultura e identidade e seu perfil atual no cenário global.

Os excertos a seguir tanto confirmam a lacuna na formação docente, nas esferas política e pedagógica, como atestam a falta de material e sinalizam a ausência de um planejamento oficial coeso que ofereça suporte às políticas explícitas ou, no caso das ações não-oficiais, parâmetros que considerem a especificidade do PLE:

Sou Leitora do governo brasileiro [...] Quanto ao material didático na área é um grande problema, pois trabalho em uma ilha do Caribe anglófono e o material didático não chega a tempo para as aulas. 
Tentamos criar nosso próprio material com base em livros do Centro de Línguas da Universidade. (39EV17a/USA-Iof)

Aqui na Espanha é escasso. Eu acho que até o A1, A2, pode ter. No mais...a partir do B1, o material é pobre. Os exercícios não são desafiadores... o aluno... ele quer uma coisa inteligente... o aluno quer ir a mais... não quer ficar "meia boca". A pessoa que tá aprendendo português ele fala no mínimo dois idiomas e o PLE vai ser o terceiro, mais um. Então, ele quer ... eu acho que... é... são muitos níveis, mas um material completo como o QECR pede eu não vi ainda. Pode ser que exista, mas eu não conheço. (04P04a/ESP-Ipr)

Boa e precária, ao mesmo tempo. Muita demanda sem opção de material didático e professores sem capacitação, sem apoio do governo brasileiro para esta comunidade. (34EV15a/PER-Ipr)

As condições são insatisfatórias, o material didático é escasso e pouco interessante, embora haja muita procura para o aprendizado do idioma. São poucos os livros didáticos que estão estruturados conforme o Quadro Comum Europeu de Referência. (35EV18a/ITL-Ipr).

Ao reportarem as dificuldades advindas da falta do material didático, os entrevistados reafirmaram a necessidade de uma linha de ação comum aos docentes que atuam na área, seja na esfera oficial ou na privada. Os professores entrevistados reconhecem a contribuição do Quadro Comum de Referência Europeu (QCRE) ${ }^{3}$, em relação aos parâmetros de avaliação da proficiência em português, em meio a tantas carências, embora reconheçam a necessidade de ajustes do instrumento, pela diversidade na interpretação dos níveis, além da adequação ao espaço geolinguístico, onde o idioma é ensinado:

O Quadro ajuda... é uma referência. O Quadro conseguiu o que penso que se poderia fazer com a Língua Portuguesa... um quadro que todos seguimos, adotarmos. Podemos ... O professor pode não concordar com algumas coisas, mas temos ai umas referências, uns níveis, umas competências, uns objetivos. Isso seria bom, um nível, com referências... é isso que devemos fazer em relação ao português:

\footnotetext{
${ }^{3}$ O Quadro Europeu Comum de Referência para as Línguas (QECR), de 2001, é um documento do Conselho da Europa, elaborado no âmbito do Projeto Políticas Linguísticas para uma Europa Plurilingue e Multicultural, que define seis diferentes níveis de referência para a avaliação do nível de proficiência em uma língua estrangeira. Disponível em: http://www.dge.mec.pt/quadro-europeu-comum-de-referencia-para-linguas Acesso em: agosto de 2018.
} 
uma referência comum, que todos respeitem... deve ser uma instituição e, por isto, o Instituto Internacional, onde estejam todos os países de Língua Portuguesa, todos com a mesma responsabilidade...deveria ser uma instituição onde estivessem acadêmicos, linguistas, representantes de todos os países para que ninguém... nenhum sinta que está fora, um grupo de pessoas que deveria estar COEeso, com uma acreditação, com um nível, uma experiência... isso seria bom. (01P20a/ESP-Iof)

Este Quadro pode nos servir de referência sim, como faz com o ensino de língua estrangeira em muitos países. É uma questão de adequação. Por exemplo, para atingir o nível A2 de PLE o aluno precise de capacidades diferentes do Alemão como língua estrangeira. É necessário que se defina primeiro as necessidades linguísticas relativas a cada uma das capacidades comunicativas pertinentes a cada nível. (08P30a/DEU-Ipr)

Devem ser reforçados estes parâmetros já que alguns livros não definem quando tem sido atingido os diversos níveis de proficiencia d'acordo ao Quadro Comum de Referência. Essa é minha opinião. (32EV03a/PER-Ipr)

[...] na Europa, o Quadro Comum europeu para ensino do PLE me parece bem eficiente. Não é uma realidade no continente americano, mas é um sistema bem organizado que poderia ser aproveitado aqui também. (08EV05a-Iof)

Diniz (2012), identifica a falta de um alinhamento para as ações dos Leitorados brasileiros e traz à tona uma discussão acerca do assujeitamento do Leitor, um agente de uma política linguística, aos fatores sociais, econômicos e políticos que atuam sobre a língua, visto que as ações oficiais ocorrem em função de tais fatores e, ao mesmo tempo, estão à mercê de seus desdobramentos para se tornarem exequíveis e consistentes.

Desse modo, a falta de incentivo à elaboração e aquisição de material didático, a ausência de parâmetros de ação no tocante à promoção da língua e a disparidade dos provimentos recebidos pelos leitores podem resultar na subvalorização da língua ou, conforme defende o autor, no mascaramento das intenções do Estado brasileiro, em relação ao valor estratégico do português.

Para alguns entrevistados, no tocante ao Estado brasileiro, falta uma ação mais uniforme, por parte da Divisão pela Promoção da Língua Portuguesa (DPLP), no 
Itamaraty, na distribuição de recursos aos Postos de trabalho, de forma que as necessidades de cada espaço sejam atendidas de modo equânime e não em função do destaque que o país apresenta, em um determinado contexto:

O problema é que o Brasil aplica recursos em países cujo progresso está visível na mídia, onde os cantores e artistas famosos fazem shows. [...] No meu caso, quando vejo o site do Leitorado, vejo os incentivos para os Estados Unidos e posso garantir que é real porque já trabalhei com o ensino de PLE nos Estados Unidos e tínhamos tudo o que pedíamos para a embaixada. Por isso, mais uma vez volto a dizer que não há vontade política. (39EV17a//USA-Iof)

Neste sentido, a semelhança entre os dois Leitorados fica diluída, visto que a divulgação cultural é o eixo central da ação brasileira, segundo a DPLP, enquanto o Camões - Instituto da Cooperação e da Língua, (doravante IC), atualmente sob a tutela dos Ministério dos Negócios Estrangeiros, tem como foco principal o ensino, seja em universidades e nos centros de língua, além da formação de professores e da avaliação da proficiência em português, realizada em dois instrumentos diferentes, de acordo com o público-alvo, conforme declarações de um gestor e de professores que atuam nos EUA e na Alemanha:

[...] portanto, temos que ter a visão estratégica de perceber que em aprendendo português, há uma aprendizagem com objetivos estratégicos importantes nas relações entre países que não falam português e os que falam. O desenvolvimento que a China está a ter, em relação ao português, é um grande exemplo [...] Mas, voltando... é... àquela primeira das quatro ações - com licença, quero reforçar... é... - a que referimos no início: um quadro de referência para o ensino do português, que nós temos, ao qual tomamos como referência o interesse dos alunos que estão nas Diásporas e que, portanto, nos dá uma visão do português como PLH - é o QuaREPE - que já está no início de sua regulamentação no Ministério da Educação, em que assumimos como fator de crescimento a qualificação para o ensino e, com ele, também as provas de proficiência linguística (03G15a/PRT-Iof).

Percebe-se, na prática, que cada Leitor tem seu trabalho pulverizado em diferentes âmbitos, em função de uma política de trabalho estabelecida pela universidade-parceira ou 
pelo Estado, em que o ensino de um português pluricêntrico é inviabilizado, em uma ação que se movimenta no contra fluxo das percepções de gestores e professores que representam as políticas implícitas relacionadas ao português:

[...] o português é língua oficial em vinte e seis organizações, mas em pelo menos a metade, o português não é devidamente ancorado em práticas de uso. [...] A hipótese é de que não podemos descuidar das organizações onde o português já é língua oficial (...) com um plano concreto para que a LP seja efetivamente usada, pois dará à língua sustentação para um voo mais alto. Veja o caso do Fórum de Macau: não é da CPLP, mas, especificamente, pela China - Região Administrativa Especial de Macau - mas que tem a preocupação em colocar a LP em evidência na Ásia e, certamente, o que tem sido feito por lá pode ser feito nas outras organizações. (02G25a /PRTIof)

O que se poderia fazer? Penso que o primeiro pode ser o Instituto Internacional da Língua ou uma instituição deste tipo ... fizesse uma política global do ensino da língua, com um material geral para o ensino da língua, que não fosse o $\mathrm{PE}$ ou o PB, mas o Português e, conforme o nível, o aluno deveria conhecer mais sobre as diferenças, mas a língua é a mesma com essas indicações.... É, isso seria o primeiro: uma política conjunta, com uma instituição para o Português como língua única. E penso que todos ganhariam. Portugal, Brasil, ganhariam os africanos. Penso que haveria uma política uniforme, comum, dentre todos os países de LP. (01P20a/ ESP-Iof)

Paradoxalmente, na Galiza as condições para aprender português são ótimas do ponto de vista do cohecimento passivo da língua de qualquer galego; porém as possibilidades de o ensinar na educação secundária são mesmo difíceis: apesar da procura crescente de parte do alunado, ainda não existem vagas para o professorado que, para o lecionar, deve superar numerosos entraves administrativos. No que diz respeito ao material didático e à formação, depende do interesse e empenho pessoal do docente ao ser escassa a oferta pública. Apenas a proximidade física com Portugal, a internet e o trabalho de empresas privadas ou coletivos culturais aliviam as carências. (12P14a/GLZ-Iof)

Ainda falta muito material, se compararmos com o que encontramos no ensino de outras línguas, como o inglês, alemão e espanhol. Também acredito que os alunos não encontram com facilidade profissionais bem formados, com experiência didática de PLE, e acabam aprendendo com simples falantes nativos de Português, que na maioria das vezes não têm uma base linguística para oferecer. (08P30a/DEU-Ipr) 
Entre os professores convidados a tratar do tema, a formação assume um aspecto singular, em que a opção pela formação divide o grupo, denotando, de certa forma, a falta de uma visão estratégica da relevância do trabalho do professor de PLE, para o fortalecimento de um nicho no mercado de trabalho, conforme afirmou uma das entrevistadas, ao analisar as condições para o ensino de PLE, considerando a oferta e a procura:

Este é o meu quarto ano como professora de PLE e eu não dou conta. Na semana passada, vieram quatro ofertas de lugares diferentes... Então, uma professora recomenda... a escola te chama... Então, demanda tem. Mas os professores precisam ser um pouco mais vendedores, estratégicos... precisam saber negociar preço. Pelo menos 20 euros ou 15. Não é o euro. Tem demanda e os professores precisam ter mais estratégias de mercado, ter um preparo anterior. (04P04a/ESP-Ipr)

Os grupos de entrevistados revelaram em seus depoimentos uma visão promissora desse mercado, ao mesmo tempo em que salientaram a importância da preparação do professor de PLE. Além disso, grande parte se ressente da falta de apoio oficial a suas demandas essenciais, como uma formação específica para PLE e seus desdobramentos. Nesse contexto, percebemos as divergências entre os propósitos das políticas oficiais e as lacunas deixadas pelas instituições responsáveis por essas ações, em um atraso considerável, quando comparadas a outras políticas em torno da difusão internacional de outros idiomas, por exemplo:

[Em relação à formação] Nunca vi em minha vida. Inglês, sim. Mas LP, nunca. Já tentamos fazer reuniões... mas falta um coordenador acadêmico... se não há diretrizes, cada um faz como quiser. Vimos isso na reunião outro dia, na Casa do Brasil: o professor tem liberdade pra fazer o que quiser, mas ele faz assim porque não tem uma formação. Outro dia, em outra escola, vi uma preparação para inglês... no português não há e eu gostaria de participar de um trabalho assim. (04P04a/ESP-Ipr)

Sim, uma formação específica seria ideal e, muito melhor se fosse considerada a nacionalidade do aluno-perfil, já que não é igual dar 
aulas a um hispano-falante e a um japonês, por exemplo. Acho importantíssimo o professor conhecer muito bem a língua do alunoperfil, só assim ele pode compreender por que e como eles acabam fazendo suas confusões e só assim ele pode orientar de forma certeira. [...] Não há. Em 23 anos, esta é a primeira vez que algum organismo oficial se interessa pelo trabalho que eu desenvolvo. Eu podia até estar fazendo tudo errado e estaria fazendo sem o menor controle ou orientação. Cada vez que tentei obter ajuda didática, por exemplo, as ideias eram ultrapassadas e muito acadêmicas, fugindo completamente à realidade do meu aluno-perfil, fato que me obrigou a criar meu material - Lengua Portuguesa para hispanohablantes. (07P23a/ESP-Ipr)

A voz dos nossos entrevistados representam uma amostra de profissionais comprometidos com a difusão e promoção internacional do português e, ao divulgá-las, não desconhecemos a existência de Cursos de Formação de Professores, nos moldes oferecidos seja pelas universidades brasileiras, tais como a Universidade de Brasília (UnB) ou a Universidade Federal da Bahia (UFBA), para citar algumas, ou pelas instituições oficiais como o IC, nas modalidades presencial e virtual, ou as formações do Instituto Internacional da Língua portuguesa (IILP), mas pretendemos ressaltar a urgência de ações partilhadas por essa comunidade que integra essa lusosfera contemporânea, em que as convergências sejam afinadas e divergências sejam respeitadas.

As convergências já trazem frutos, mas ainda são medianas, conforme sinalizou Almeida Filhos em suas primeiras apreciações sobre o tema. As dimensões dessas PL, com foco tanto na forma como no estatuto da língua, ainda revelam a necessidade de uma coesão de forças entre os países que compartilham o uso do português, mesmo que atribuam estatutos distintos à língua, mas tenham como premissa o reconhecimento do peso da língua, nos aspectos, políticos, sociais e ideológicos, na esteira do que preconizou um dos gestores entrevistados que, a nosso ver, respalda a posição desse grupo:

Tudo isto, eu estou dizendo, pra mostrar os indícios deste português do século XXI, um português para onde estamos nos encaminhando em que nós dividimos o preço, o custo da instrumentação linguística, (inaudível) que vai se tornando cada vez mais importante no eixo do letramento digital, nesta sociedade da informação, na sociedade do conhecimento. Nós não podemos mais prescindir de uma preparação do corpus da LP, de maneira a estarmos presentes na 
instrumentação contemporânea da internet, sem o que os nossos cidadãos terão sempre que buscar na biblioteca virtual, em que precisarão se valer de outra língua, para poder ter acesso ao conhecimento, porque não fomos capazes de municiá-lo, concretamente, com o que é necessário à vida contemporânea (02G25a-Iof).

Desse modo, com base na engrenagem apresentada no início do texto, além da influência do contexto social e das ideologias que norteiam a elaboração das ações oficiais, convém considerar as políticas implícitas, aqui representadas nas concepções e práticas dos gestores e professores de PLE que atuam, prioritariamente, na divulgação da língua e da cultura lusitana, com vistas a sedimentar o português em sua configuração transcontinental.

\section{Considerações finais}

As afirmações colhidas entre os entrevistados denotam a necessidade premente de uma coesão de forças entre os países em que a língua portuguesa tem força aglutinadora para, em conjunto, desenvolverem uma PL que atenda aos gestores e professores, para além dos gabinetes. O foco dessas políticas linguísticas deve convergir para a ocupação de espaços, muitas vezes "esquecidos", no planejamento de ações oficiais tais como o ensino, a produção e o acesso ao material didático, reforçando a necessidade de uma visão estratégica sobre o peso do português, em uma sociedade globalizada.

Em meio a tantas exigências, as políticas implícitas, conforme visto no diagrama 1, aparecem no contra fluxo das ações oficiais e, desse modo, podem funcionar como fator interveniente no processo de internacionalização de uma língua, uma vez que podem emperrar o processo ou contribuir para acelerar a mobilidade da engrenagem, por serem resultantes de fatores socioeconômicos, históricos e culturais que, por sua vez, interferem na elaboração, implementação e vitalidade das políticas linguísticas. 


\section{CONVERGENT AND DIVERGENT LANGUAGE POLICIES IN THE TEACHING OF PORTUGUESE - FOREIGN LANGUAGE}

ABSTRACT: In this article, we present the beliefs and practices of teachers who work in the promotion of Portuguese in the international scenario, in order to register the vision of these professionals about instruments essential to the diffusion of Portuguese, in the current scenario. From the perspective of Spolsky (2004), to whom a Linguistic Policy (PL) should not disregard its agents, we then analyze the Lectorate Programs, the shortage of didactic material and the incipient training of teachers, as tools to promote Portuguese. In tracing this situation, we conclude that there is a gap between official policies and the needs of professors working in this area in general. Therefore, with this reflection, we aim to contribute to reducing the gap between these official actions and practices of these professionals, as well as reinforce the need for an increase in political-pedagogical training of the groups responsible of the promotion of a language with the characteristics of Portuguese.

KEYWORDS: Language policy; Linguistic management; Teaching of Portuguese as foreign language.

\section{REFERÊNCIAS}

ALMEIDA FILHO, José Carlos P. (org.) Parâmetros atuais para o ensino de PLE: português: lingua estrangeira. Campinas, São Paulo: Pontes, 2009.

. Fundamentos de Abordagem e Formação no ensino de PLE e de Outras Línguas. Campinas-São Paulo: Pontes Editores, 2011.

BONACINA-POUGH, Florence. Researching 'practiced language policies': Insights from Conversation Analysis. In: Language Policy, n.11, 2012, p. 213-234.

BOURDIEU, Pierre. A economia das trocas linguísticas. São Paulo: EdUsp, 1996.

CALVET, Louis-Jean. As politicas linguísticas. Prefácio de Gilvan Muller. Trad. : Isabel Oliveira Duarte, Jonas Tenfen e Marcos Bagno. São Paulo: Parábola Editorial: IPOL. 2007.

DINIZ, Leandro Rodrigues Alves. Política linguística do Estado brasileiro na Contemporaneidade: a institucionalização de mecanismos de promoção da língua nacional no exterior. Tese. Campinas, 2012.

FIORIN, José Luiz. Língua, discurso e política. Alea [online]. 2009, vol. 11, n. 1, p. 148165. ISSN 1517-106X. http://dx.doi.org/10.1590/S1517-106X2009000100012. Acesso em 16/08/2018.

SCHIFFMAN, H. F. Linguistic culture and language policy. London;New York: Routledge, 2002.

SHOHAMY, E. Language policy: hidden agendas and new aproaches. London/New York: Routledge, 2006. 
SILVA, Mário J. F. Promoção da língua portuguesa no mundo: hipótese de modelo estratégico. Tese de doutoramento em Estudos Portugueses. Lisboa: Universidade Aberta, 2005.

SPOLSKY, Bernard. Language policy. New York: Cambridge University Press, 2004. Language management. New York: Cambridge University Press, 2009.

Recebido em: 01/06/2018. Aprovado em: 15/08/2018. 